\title{
A Comparison of the Polygalacturonases Produced in vivo and in vitro by Penicillium expansum Thom.
}

\author{
By T. R. SWINBURNE \\ Plant Pathology Research Division, Ministry of Agriculture for Northern Ireland \\ and School of Agriculture, Queen's University, Belfast \\ AND M. E. CORDEN \\ Botany and Plant Pathology Department, Oregon State University, \\ Oregon, U.S.A.
}

(Accepted for publication 23 August 1968)

SUMMARY

\begin{abstract}
Polygalacturonase (PG) was produced by Penicillium expansum in rotted apples and in liquid culture medium containing pectin; acetone precipitates of the enzyme were prepared from both sources. The PG extracted from apples (in vivo $\mathrm{PG}$ ) behaved as an endo-PG and degraded sodium polypectate to tetragalacturonic acid. PG from culture filtrates (in vitro $P G$ ) before purification had quite different properties, the final hydrolysis product being monogalacturonic acid. PG from both sources was purified by ion-exchange chromatography. The properties of some purified PG preparations were quite different from those of the crude material. None of the purified in vitro PG released monogalacturonic acid from sodium polypectate, whilst some preparations from both sources had identical endo-PG properties after purification. Changes in the properties of endo-PG produced in vivo and in vitro were apparent during purification and a series of distinct endo-PG's were obtained which yielded unresolved oligomers, tri- or tetragalacturonic acid as final hydrolysis products. It is suggested that the changes in behaviour of the various PG preparations during purification were brought about by changes in the molecular configuration of the enzyme, and that such changes could account for some of the variability between enzymes produced in vivo and in vitro.
\end{abstract}

\section{INTRODUCTION}

Pectic glycosidases (poly $\alpha$-I, 4-galacturonide glycano hydrolase E.C. 3.2 . I . I 5) have been classified according to their substrate specificity and the position of the bonds which they hydrolyse. Thus polygalacturonases (PG) preferentially attack pectic acid whilst polymethylgalacturonases (PMG) preferentially attack pectins of high methoxyl content. Endo-PG and endo-PMG were further defined as hydrolysing the $\alpha-1,4^{-}$ glycosidic bonds in the substrate at random, whilst exo-PG and exo-PMG hydrolyse the terminal link (Demain \& Phaff, 1957). Poly $\alpha-1,4-D$-galacturonide lyases (E.C. 4.2 .99.3) have been similarly classified (Bateman \& Millar, I966). It has been inferred that pectic enzymes produced by the pathogen are involved in the development of plant disease in a variety of host/pathogen combinations (Husain \& Kelman, 1959), particularly for soft rots of fleshy organs. Difficulties in assessing the individual role of these enzymes are primarily due to problems of extraction from host tissue, resulting 
from inactivation by oxidised host polyphenols (Akinrefon, 1967), and this has frequently led to the use of in vitro produced enzymes in experimental studies. Differences between enzymes produced in vivo and in vitro have been frequently demonstrated (Bateman \& Millar, 1966). Botrytis cinerea produces different types of enzymes in culture media at various pH values (Damle, 1952) and yet different enzymes on onion leaves (Hancock, Millar \& Lorbeer, 1964). Penicillium expansum, which is responsible for considerable wastage in stored apple fruit, produced endo-polygalacturonase in vivo and endo-polymethyl-galacturonase in vitro where pectin was the sole carbon source (Cole \& Wood, 196I). Oxidation of polyphenolic materials does not occur to any great extent in $P$. expansum rotted apples, and extracts have relatively high degrees of pectic enzyme activity (Cole \& Wood, 1961). By using various separation techniques, particularly ion-exchange chromatography, isolation and purification of pectic enzyme mixtures produced simultaneously by some fungi has been achieved (Rexova-Benkova \& Slezarik, 1966; McClendon \& Kreisher, 1963; Endo, 1963), and the presence of distinct types of endo-PG demonstrated (McClendon \& Kreisher, 1963; Endo, 1963). The formation and dissociation of enzyme complexes during ion-exchange chromatography has also been recorded (Swinburne \& Corden, 1967). The objective of the present work was to separate the various PGs produced in vivo and in vitro by Penicillium expansum and to compare their properties.

\section{METHODS}

The isolate of Penicillium expansum used in this work came from a naturally rotted Bramley's Seedling apple obtained from Co. Armagh, Northern Ireland, and was maintained on $2 \%$ malt agar.

PGs produced in vitro were obtained from shake cultures grown in a modified Richards medium containing (g./l.) : $4, \mathrm{MgSO}_{4} \cdot 7 \mathrm{H}_{2} \mathrm{O} ; 5 \cdot 0, \mathrm{NH}_{4} \mathrm{NO}_{3} ; 2 \cdot 5, \mathrm{KH}_{2} \mathrm{PO}_{4}$; $0.02, \mathrm{ZnSO}_{4} ; 0.02, \mathrm{FeCl}_{3} .6 \mathrm{H}_{2} \mathrm{O}$; 10, pectin N.F. (Sunkist Inc.); in tap water. The pH value of the medium increased from 4.2 to 4.7 after 6 days' incubation at $25^{\circ}$. The organism was removed by centrifugation and discarded. Toluene $(0 \cdot 1 \%, \mathrm{v} / \mathrm{v})$ was added to the supernatant fluid as preservative and the supernatant fluid dialysed against running tap water for $18 \mathrm{hr}$. At each stage samples of the enzyme mixture were plated for sterility. Several methods for the precipitation of the PG from the dialysate were evaluated. The method finally adopted was to add slowly an equal volume of acetone at $-20^{\circ}$ to the dialysate at $0^{\circ}$. The mixture was allowed to stand for $15 \mathrm{~min}$., the precipitate removed by centrifugation and redissolved in a minimum volume of water and stored at $-20^{\circ}$. Approximately $83 \%$ of the PG, as determined viscometrically, was recovered.

Pectic enzymes produced in vivo were obtained from rotted cortical tissue removed from Bramley's Seedling apples held 15 days at $25^{\circ}$ following artificial inoculation with Penicillium expansum by a cork borer method (Granger \& Horne, 1924). The rotted tissue was first frozen to aid maceration and $2 \mathrm{~kg}$. samples homogenized with 2 $1.0 .5 \mathrm{~N}-\mathrm{NaCl}$ containing $5 \%(\mathrm{w} / \mathrm{v})$ polyvinylpyrrolidone (General Aniline and Film Co., Polyclar AT; Akinrefon, I967). The homogenate was pressed through muslin and filtered through Whatman no. I paper until a clear solution was obtained. After adding toluene $(0.1 \%, v / v)$ the filtrate was dialysed against running tap water for I $8 \mathrm{hr}$. To obtain a suitably flocculent precipitate of protein from the dialysate with 
acetone it was found necessary first to add $\mathrm{NaCl}(0.2 \mathrm{~g} . / 100 \mathrm{ml}$.) followed by 2 vol. acetone. After the precipitate had been redissolved in water, viscometric assay indicated that $88 \%$ of the original PG had been recovered.

Enzyme + substrate reaction mixtures contained $0.5 \%(\mathrm{w} / \mathrm{v})$ sodium polypectate (Sunkist), $10 \%(\mathrm{v} / \mathrm{v})$ enzyme sample in $0.1 \mathrm{M}$-sodium acetate buffer ( $\mathrm{pH} 5.0$ ) with $0.001 \%(\mathrm{v} / \mathrm{v})$ Merthiolate (Eli Lilly and Co.) as a preservative. Controls contained boiled enzyme or an equivalent volume of water. For viscosity decrease assays $8 \mathrm{ml}$. samples of the reaction mixture previously equilibrated to $37.5^{\circ}$ were rapidly transferred to Cannon-Fenske viscometers (size 200) and the time taken $(t)$ for the relative viscosity to fall to $50 \%\left(\eta R_{50}\right)$ of the initial value determined by the method of Wood (1955). Units of PG activity were calculated as 1000/t. Release of reducing groups in various enzyme + substrate reaction mixtures incubated at $37.5^{\circ}$ were determined colorimetrically with dinitrosalicylic acid reagent (Miller, 1959) and calculated as $\mu \mathrm{g}$. galacturonic acid $/ \mathrm{ml}$. The percentage of galacturonic acid anhydride units in the sample of sodium polypectate used throughout these studies was estimated with carbazole reagent (Cole \& Wood, 196I) to be $63.3 \%(w / w)$. The quantity of galacturonic acid that would be present in the enzyme + substrate reaction mixture when the hydrolysis was complete was calculated from this, and the hydrolysis at any stage was calculated as $\%$ of the galacturonic acid equivalent found by reducing-group methods of this quantity. For determinations of $\%$ hydrolysis at $\eta R_{50}$ viscometric and reducinggroup assays were made simultaneously on the same reaction mixture.

Hydrolytic products in the reaction mixtures were identified chromatographically (Young \& Corden, 1964). Reference spots of authentic monogalacturonic acid were included on each paper. Other oligomers were identified by their $R_{F}$ values, and the identification was checked by calculating the $R \mathrm{~m}$ value, where $R \mathrm{~m}=\log \left(\left[I / R_{F}\right]-\mathrm{I}\right)$ (Bate-Smith \& Westall, 1950). A linear relationship between $R \mathrm{~m}$ and the number of galacturonic acid residues in each oligomer to pentagalacturonic acid was found.

Molecular exclusion chromatography of various PG preparations were done on columns of Sephadex G-200 (Pharmacia Ltd.) equilibrated with 0. I M-sodium acetate buffer ( $\mathrm{pH} 5^{\circ}$ ) . A column $42 \times 2.5 \mathrm{~cm}$. was prepared and fitted with a water jacket which enabled separations to be carried out at $10^{\circ}$. Samples containing PG were brought to approximately $5 \%(\mathrm{w} / \mathrm{v})$ sucrose to increase their density and $3 \mathrm{ml}$. samples were layered by syringe pipette on top of the column beneath the eluant head. The column was eluted with the buffer at a rate of approximately $10 \mathrm{ml}$./ $\mathrm{hr}$ and $4.4 \mathrm{ml}$. fractions collected.

Ion-exchange chromatography of the various PG preparations were done on columns of either diethylaminoethylcellulose (DEAE-cellulose; Whatman D.E. 52) or carboxymethylcellulose (CM-cellulose; Whatman CM. 52). After precycling the exchangers according to the manufacturers' instructions, DEAE cellulose was equilibrated with tris- $\mathrm{HCl}$ buffer $(\mathrm{pH} 7.0 ; I=0.05)$ and $\mathrm{CM}$ cellulose was equilibrated with $0.0 \mathrm{O} \mathrm{M}$ sodium acetate buffer $\left(\mathrm{pH} 5^{\circ}\right)^{\circ}$. Columns 45 to $50 \mathrm{~cm} . \times 2 \mathrm{~cm}$. were prepared from each of the exchangers, and $10 \mathrm{ml}$. samples containing PG applied. Eluant was delivered, at room temperature, to the column by a peristaltic pump at a flow rate of approximately $80 \mathrm{ml} . / \mathrm{hr}$ and consisted of buffer with a linear gradient of sodium chloride concentration. Fractions of $10.8 \mathrm{ml}$. were collected.

PG in the fractions collected from the various columns was assayed by a cup-plate method (Dingle, Reid \& Solomons, 1953). A dilution series of the enzyme applied to 
the column was included on each plate, enabling the relative \% PG concentration of each fraction and the over-all recovery to be estimated. The presence of sodium chloride in enzyme preparations did not alter the size of the halos they produced in this assay.

Fractions within individual peaks of $P G$ eluted from the various columns were bulked and concentrated to approximately the volume of the original sample by dialysis against Carbowax $20 \mathrm{M}$. in Visking tubing at $2^{\circ}$. The concentrates were then stored at $-20^{\circ}$.

Protein concentrations were estimated by determining the extinction at 260 and $280 \mathrm{~m} \mu$ (Beckman D.B.-G.) and reference to the data of Warburg \& Christian (1942).

\section{RESULTS}

\section{Properties of the crude in vivo and in vitro $P G$ preparations}

The crude in vitro $\mathrm{PG}$ contained $0 \cdot 10$ unit $\mathrm{PG} / \mu \mathrm{g}$. protein and the in vivo preparation 0.36 unit/ $\mu \mathrm{g}$. protein, as determined viscometrically with sodium polypectate as substrate. When pectin was used as the substrate the viscometric activities of both preparations were approximately $5 \%$ of these values, indicating that PMG was not present in either.

No enzymes of the transeliminase type were detected by the micromethod of Ayers, Papavizas \& Diem (1966) in either preparation incubated with pectin or sodium polypectate at $\mathrm{pH} 5 \cdot 0$ or $8 \cdot 0$.

Table I. The hydrolysis of sodium polypectate by crude in vivo and in vitro $P G$ of Penicillium expansum and the nature of the hydrolytic products

\begin{tabular}{|c|c|c|c|c|c|c|c|c|c|c|c|c|c|c|}
\hline \multirow{3}{*}{$\begin{array}{c}\text { Time } \\
\text { (hr) }\end{array}$} & \multicolumn{7}{|c|}{ Crude in vivo $\mathrm{PG}$} & \multicolumn{7}{|c|}{ Crude in vitro $\mathrm{PG}$} \\
\hline & \multirow{2}{*}{$\begin{array}{c}\% \\
\text { Hydrolysis }\end{array}$} & \multicolumn{5}{|c|}{ Hydrolytic products* } & \multirow[b]{2}{*}{ FR } & \multirow{2}{*}{$\begin{array}{c}\% \\
\text { hydrolysis }\end{array}$} & \multicolumn{5}{|c|}{ Hydrolytic products* } & \multirow[b]{2}{*}{ FR } \\
\hline & & $\mathbf{I}$ & 2 & 3 & 4 & 5 & & & $\mathbf{I}$ & 2 & 3 & 4 & 5 & \\
\hline $\mathbf{I}$ & $40 \cdot 6$ & - & - & + & + & ++ & + & $64 \cdot 9$ & + & \pm & \pm & + & + & + \\
\hline 4 & $50 \cdot 8$ & \pm & - & + & ++ & + & + & $75 \cdot I$ & +++ & $\overline{-}$ & - & - & - & \pm \\
\hline 8 & $50 \cdot 1$ & . & . & . & . & . & . & $78 \cdot 2$ & . & . & . & . & . & . \\
\hline 10 & . & + & - & + & ++ & \pm & + & . & +++ & - & - & - & - & - \\
\hline 24 & $52 \cdot 0$ & + & 一 & + & +++ & - & - & $92 \cdot 2$ & +++ & - & - & - & - & - \\
\hline
\end{tabular}

* Columns I to 5 mono- to penta-galacturonic acid; FR, unresolved oligomers; -, none detected; \pm , trace; ++ , relative concentration.

The hydrolysis of sodium polypectate by both enzyme preparations was followed over a $24 \mathrm{hr}$ period, and the nature of the breakdown products was determined (Table I). Monogalacturonic acid was the principal hydrolytic product released by the in vitro PG and virtually the only compound detectable after $4 \mathrm{hr}$ incubation. The hydrolysis by the in vitro PG had reached $92 \%$ after $24 \mathrm{hr}$ and would probably have been completed in a longer time. With the in vivo PG, however, only slight increase in hydrolysis occurred after $4 \mathrm{hr}$ incubation when approximately half the available substrate bonds had been hydrolysed. Monogalacturonic acid in small quantities was detected at the later stages of hydrolysis, but the principal breakdown product was tetragalacturonic acid, with a small amount of trigalacturonic acid found at all stages (Table I).

The difference between the crude in vitro and in vivo $\mathbf{P G}$ was further illustrated by 
the values of the $\%$ hydrolysis of sodium polypectate at $\eta R_{50}$ for both enzymes (Table 4). Thus crude in vitro PG hydrolysed more than three times as many bonds as the crude in vivo $P G$ to achieve the same reduction in viscosity.

Single peaks of PG were separated from both crude in vivo and in vitro preparations on Sephadex G. 200 (Fig. I). The elution volumes of PG from both sources were almost identical, the average of duplicate experiments being $154 \mathrm{ml}$. for in vitro PG and $156 \mathrm{ml}$. for in vivo PG. Approximately quantitative recovery of PG was obtained from both preparations. Non-enzyme protein was eluted immediately following the void volume of the column and after the PG peaks from both crude preparations (Fig. I). Rechromatography of the PG within each peak on Sephadex G. 200 resulted in elution at the same volume for each.

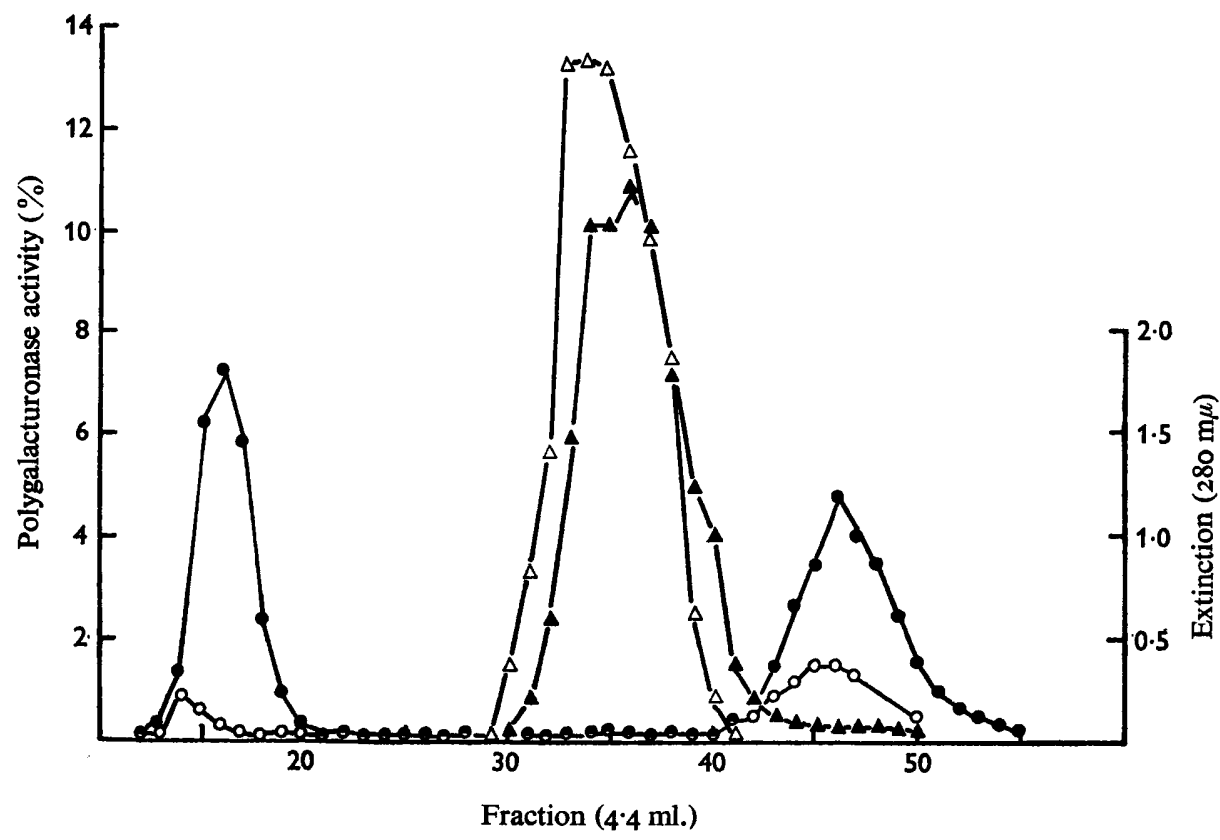

Fig. I. Elution of PG produced in vitro and in vivo by Penicillium expansum from a column of Sephadex G. 200. PG activity is expressed as a \% of the sample applied; - $\Delta-$, in vivo PG; $-\triangle$ - in vitro PG. Extinction values at $280 \mathrm{~m} \mu$ of fractions shown as - - for in vivo preparation, - - - for in vitro preparation.

\section{$D E A E$-cellulose chromatography of crude in vivo and in vitro $P G$}

None of the PG in the in vivo preparation was retained by DEAE-cellulose, but was eluted in a single peak with the void volume (Fig. 2). Most of the protein was adsorbed and eluted as a single peak after the PG. In three separate experiments $74-75 \%$ of the in vivo $P G$ applied to the columns was recovered, representing about a 200-fold purification. Likewise the PG in the crude in vitro preparations passed through DEAE-cellulose columns with the void volume and was eluted as a single peak whilst most of the protein was adsorbed and eluted at a higher salt concentration (Fig. 2). Recovery of in vitro PG from these columns was somewhat variable, the average of three experiments being I0I \%, representing a threefold purification. 
After concentrating the preparations eluted from DEAE-cellulose of in vitro and in vivo PG, henceforward referred to as in vitro and in vivo DEAE-PG, respectively, to their original volume, they were separately applied to the Sephadex G. 200 column. The in vitro DEAE-PG was eluted in a single peak with an elution volume of I54 ml., which was identical to that of the crude in vitro PG. The in vivo DEAE-PG was similarly eluted as a single peak with an elution volume of approximately $157 \mathrm{ml}$. which corresponded closely to that obtained for the crude enzyme. The $\%$ hydrolysis with time of sodium polypectate by in vitro and in vivo DEAE-PG was followed, the nature of the hydrolytic products determined, and the value of the percentage hydrolysis at $\eta R_{50}$ was obtained (Table 2).
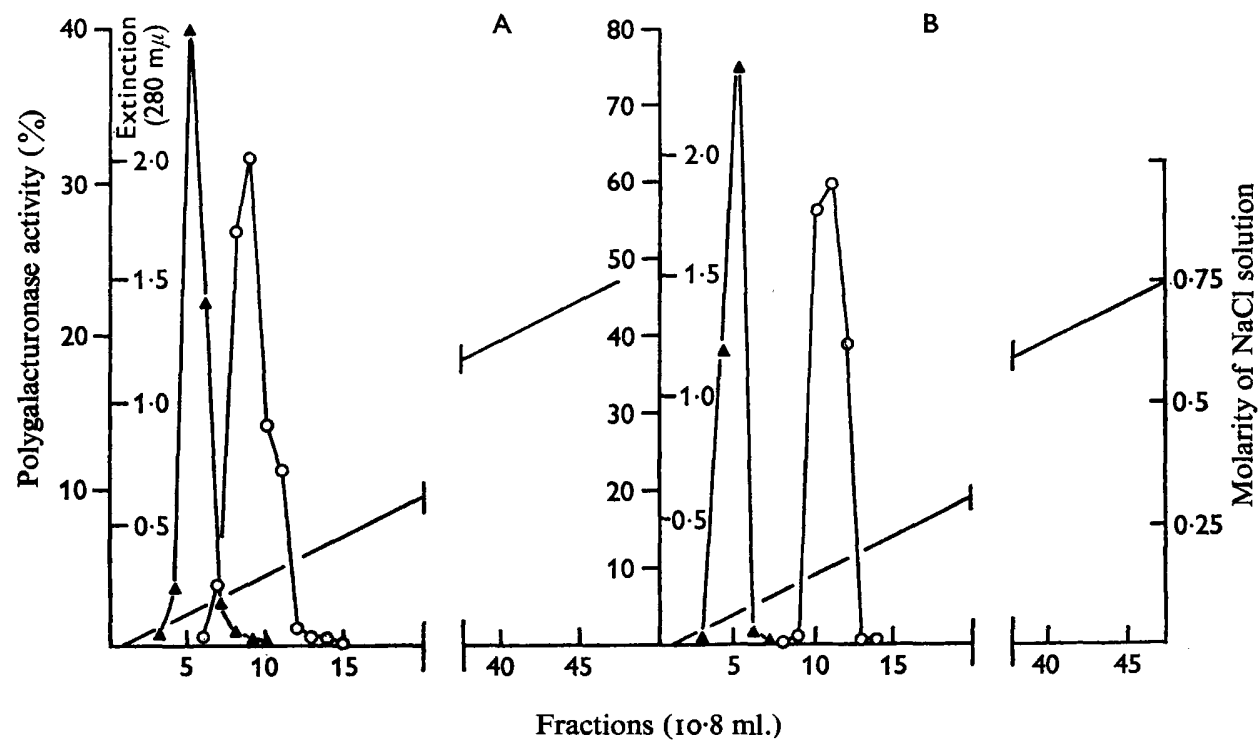

Fig. 2. Purification of $P G$ produced in vitro and in vivo by Penicillium expansum on columns of DEAE-cellulose eluted with Tris- $\mathrm{HCl}$ buffer $\mathrm{pH} \mathrm{7.0}$ and a linear gradient of sodium chloride. $\mathrm{A}$, in vivo preparation; $\mathrm{B}$, in vitro preparation. - $\mathbf{A}-, \mathbf{P G}$ activity expressed as a $\%$ of the sample applied to the column; - - -, extinction value at $280 \mathrm{~m} \mu$. Approximate salt concentrations shown by solid line.

Table 2. The hydrolysis of sodium polypectate by in vivo and in vitro DEAE-PG of Penicillium expansum and the nature of the hydrolysis products
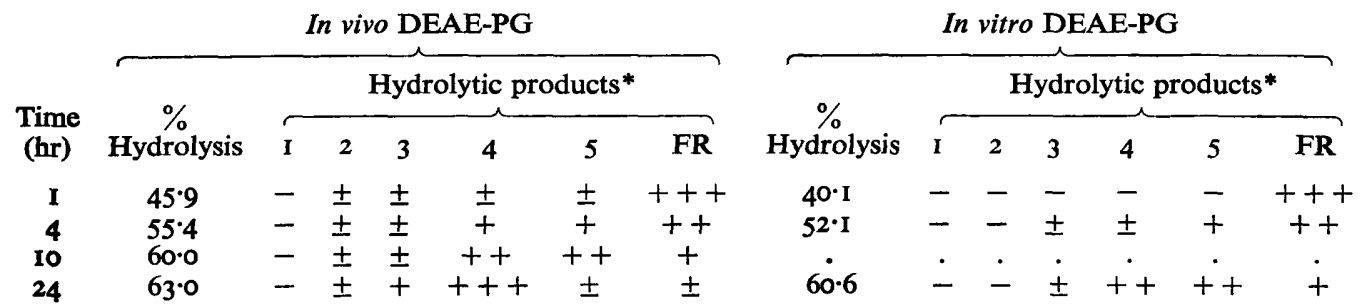

* Columns I to 5 mono- to penta-galacturonic acid; FR, unresolved oligomers; -, no detected; \pm , trai ++ , relative concentration. 
The final \% hydrolysis of the substrate achieved by the in vivo DEAE-PG after $24 \mathrm{hr}$ was higher than with the crude in vivo PG, although the principal hydrolytic products that accumulated, namely tetra- with a little tri-galacturonic acid, were the same for both preparations. Monogalacturonic acid was not detected at any stage of the hydrolysis, although a trace of digalacturonic acid was present throughout. There was no significant difference between the values of the $\%$ hydrolysis at the point where $50 \%$ viscosity loss occurred for crude in vivo PG and for in vivo DEAE-PG (Table 4).

The properties of the in vitro DEAE-PG were however quite different from those of the original crude material. The degree of hydrolysis by in vitro DEAE-PG after $24 \mathrm{hr}$ was very much less than that obtained with the crude in vitro PG (Table 2) and the principal hydrolytic products were tetra- and penta-galacturonic acids with a small quantity of trigalacturonic acid; monogalacturonic acid was not detected at any stage. This difference was also reflected in the $\%$ hydrolysis at $\eta R_{50}$, the value for the in vitro DEAE-PG was less than half that of the crude in vitro PG (Table 4). This value was also significantly different from that obtained with crude in vivo $P G$ and the in vivo DEAE-PG in spite of the similarity between the hydrolytic products released by these three enzyme preparations (Table 4).

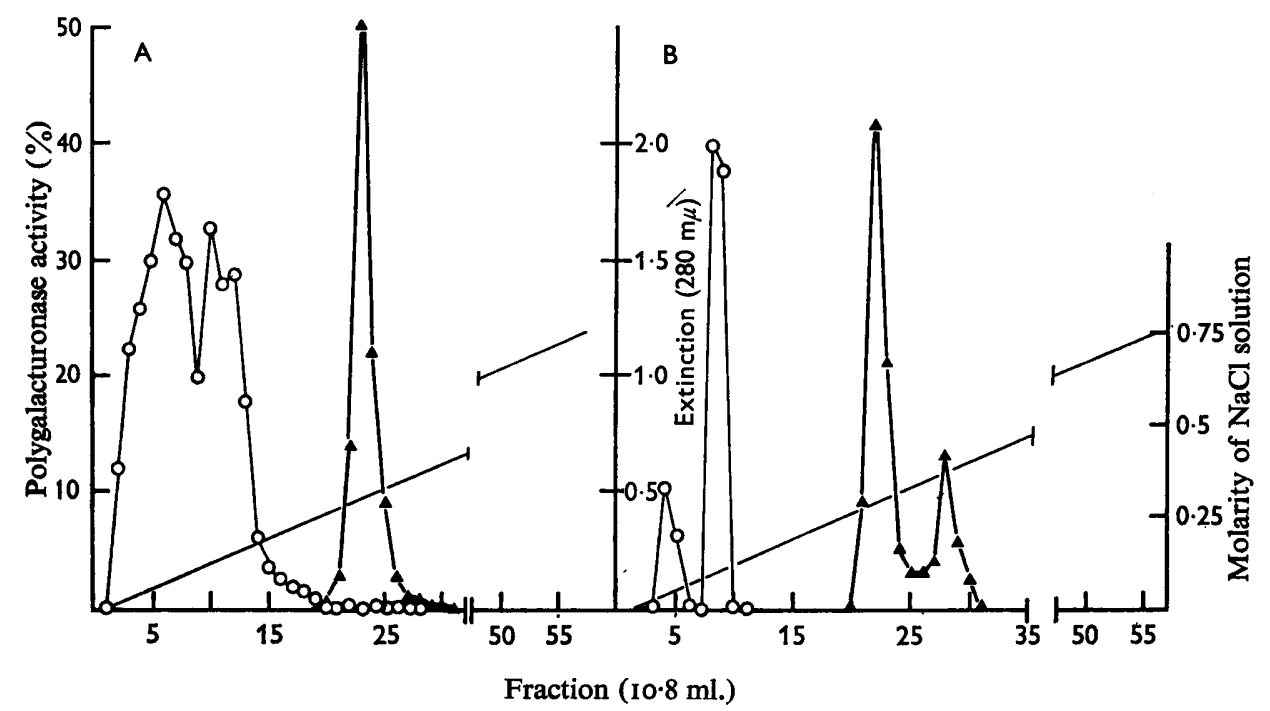

Fig. 3. Purification of PG produced in vivo and in vitro by Penicillium expansum on columns of CM-cellulose eluted with $0.01 \mathrm{M}$-sodium acetate ( $\left.\mathrm{pH}_{5 \cdot 0}\right)^{\circ}$ and a linear gradient of sodium chloride. A, in vivo preparation; $B$, in vitro preparation. - - - $P G$ activity expressed as a \% of the sample applied to the column; - - -, extinction values at $280 \mathrm{~m} \mu$. Approximate salt concentration shown as a solid line.

\section{CM-cellulose chromatography of crude in vivo and in vitro $P G$}

All the PG in the crude in vivo enzyme preparation was adsorbed on CM-cellulose columns, and eluted as a single peak by approximately $0.3 \mathrm{M}-\mathrm{NaCl}$, whilst most of the other protein was eluted at or near the void volume of the column (Fig. 3). In three separate experiments an average of $94 \%$ of the crude in vivo PG applied to these columns was recovered, representing an approximately roo-fold purification after concentration to approximately the original volume (referred to as in vivo CM-PG). 
All the PG in the crude in vitro enzyme preparation was also adsorbed on CMcellulose, but was eluted in two separate peaks (Fig. 3). The first peak was eluted by approximately $0.3 \mathrm{M}-\mathrm{NaCl}$ and contained an average of $75 \%$ of the PG recovered, whilst the second peak containing an average of $25 \%$ of the recovered PG was eluted by $0.35 \mathrm{M}-\mathrm{NaCl}$. The recovery of crude in vitro PG applied to such columns was consistently high, the average of four separate experiments being $118 \%$. Most of the inactive protein in the crude in vitro PG preparation was eluted at low salt concentrations (Fig. 3). The fractions within each peak were concentrated to approximately the volume of the original sample. The PG in the first peak, referred to as in vitro CMI-PG, represented an eightfold purification, whilst the PG in the second peak, referred to as in vitro CMII-PG, represented a fourfold purification of the original crude material.

The in vivo CM-PG was eluted from the Sephadex G. 200 column as a single peak in a volume of approximately $145 \mathrm{ml}$, which was less than the elution volume of the original crude enzyme. Similarly, the in vitro CMI-PG was eluted as a single peak in I4I ml., which was less than the crude enzyme, whilst in vitro CMII-PG was eluted as a somewhat broad peak in a volume of between 158 and $167 \mathrm{ml}$.

Table 3. The hydrolysis of sodium polypectate in vivo CM-PG and in vitro CMI-PG

\begin{tabular}{|c|c|c|c|c|c|c|c|}
\hline \multirow{3}{*}{$\begin{array}{l}\text { Time } \\
\text { (hr) }\end{array}$} & \multicolumn{6}{|c|}{ In vivo $\mathrm{CM}-\mathrm{PG}$} & \multirow[b]{3}{*}{ FR } \\
\hline & \multirow{2}{*}{$\begin{array}{c}\% \\
\text { Hydro- } \\
\text { lysis }\end{array}$} & \multicolumn{5}{|c|}{ Hydrolytic products* } & \\
\hline & & I & 2 & 3 & 4 & 5 & \\
\hline I & $55 \cdot 3$ & . & . & . & $\cdot$ & . & . \\
\hline 4 & $56 \cdot 3$ & - & \pm & \pm & + & ++ & + \\
\hline IO & $57 \cdot 6$ & - & + & ++ & + & \pm & - \\
\hline 24 & $7 \mathrm{I} \cdot 0$ & - & + & $++t$ & \pm & - & - \\
\hline
\end{tabular}

\begin{tabular}{|c|c|c|c|c|c|c|}
\hline \multicolumn{7}{|c|}{ In vitro CMI-PG } \\
\hline & \multicolumn{6}{|c|}{ Hydrolytic products* } \\
\hline lysis & I & 2 & 3 & 4 & 5 & FR \\
\hline$\cdot$ & - & - & - & - & - & $++t$ \\
\hline $37 \cdot 8$ & . & . & . & . & . & • \\
\hline 68.0 & $\dot{+}$ & \pm & \pm & $+\dot{+}$ & $\dot{-}$ & $\dot{t}$ \\
\hline
\end{tabular}

* Columns I to 5 mono- to penta-galacturonic acid; FR, unresolved oligomers; -, none detected; \pm , trace; ++ , relative concentration.

The in vivo CM-PG achieved a considerably higher \% hydrolysis of sodium polypectate in $24 \mathrm{hr}$ (Table 3) than did the crude in vivo PG (Table I). Penta- and tetragalacturonic acid were the main hydrolytic products detected after $4 \mathrm{hr}$ incubation, but at all subsequent stages of the hydrolysis only trigalacturonic remained in quantity, with some digalacturonic acid, whereas only traces of tetragalacturonic acid could be detected (Table 3). The percentage hydrolysis of sodium polypectate at $\eta R_{50}$ was twice that obtained with the crude in vivo PG and this value was also significantly different from both crude in vitro PG and in vitro DEAE-PG (Table 4).

Although the in vitro CMI-PG hydrolysed sodium polypectate more completely than the in vitro DEAE-PG (Table 2) the final \% of hydrolysis was still considerably less than had been achieved by the crude in vitro PG. Tetragalacturonic acid was the principal hydrolytic product after $24 \mathrm{hr}$ incubation. In contrast with in vitro DEAE-PG, monogalacturonic acid was present after $24 \mathrm{hr}$. The value for the $\%$ hydrolysis of sodium polypectate at $\eta R_{50}$ by in vitro CMI-PG was not significantly different from those obtained with in vitro DEAE-PG or in vivo DEAE-PG (Table 4).

The in vitro CMII-PG preparation had relatively low activity and consequently it was necessary to follow the hydrolysis of sodium polypectate over $48 \mathrm{hr}$. No hydrolytic products were detected until after $24 \mathrm{hr}$ of incubation, when $37.9 \%$ hydrolysis 
had occurred, but only unresolved oligomers were detected. During the next $24 \mathrm{hr}$ only a slight increase in hydrolysis to $43 \%$ was obtained, and no further products were detected chromatographically. The value for the $\%$ hydrolysis at $\eta R_{50}$ was the lowest obtained and significantly different from all other preparations (Table 4).

Table 4. The percentage hydrolysis of sodium polypectate by various enzyme preparations at the point where half the initial relative substrate viscosity was lost

\begin{tabular}{llcc} 
Source & \multicolumn{1}{c}{ Preparation } & $\%$ hydrolysis & $\begin{array}{c}\text { Fiducial limits } \\
(5 \%)\end{array}$ \\
In vivo & Crude precipitate & $1 \cdot 7$ & \pm 0.38 \\
& DEAE preparation & $1 \cdot 9$ & \pm 0.71 \\
& CM preparation & 4.2 & \pm 0.32 \\
In vitro & DEAE/CM preparation & $2 \cdot 0$ & \pm 0.08 \\
& Crude precipitate & 6.1 & $\pm 1 \cdot 18$ \\
& DEAE preparation & $2 \cdot 8$ & \pm 0.16 \\
& CMI preparation & $1 \cdot 8$ & \pm 0.38 \\
& CMII preparation & 0.34 & \pm 0.81 \\
& DEAE/CM preparation & 1.8 & \pm 0.10
\end{tabular}

Rechromatography of in vivo and in vitro DEAE-PG on CM cellulose

After concentration to approximately their original volume, Io $\mathrm{ml}$. of in vivo and in vitro DEAE-PG were separately applied to CM-cellulose columns which were eluted with a linear gradient of $\mathrm{NaCl}$. All the $\mathrm{PG}$ in the in vivo DEAE preparation was adsorbed on these columns and was eluted as a single peak by approximately $0.3 \mathrm{M}-\mathrm{NaCl}$, corresponding exactly to the crude in vivo PG. Approximately $105 \%$ of the in vivo DEAE-PG applied to CM cellulose columns was recovered (referred to as in vivo DEAE/CM-PG).

The $P G$ in the in vitro DEAE preparation was also adsorbed on CM cellulose, and was similarly eluted as a single peak by approximately $0.3 \mathrm{M}-\mathrm{NaCl}$. No PG peak corresponding to in vitro CMIIPG was obtained. In two experiments 72 and $82 \%$ of the in vitro DEAE-PG applied to CM cellulose columns was recovered (referred to as in vitro DEAE/CM-PG). After reconcentrating both the in vivo and in vitro DEAE/ CM-PG preparations to their original volumes they were separately applied to the Sephadex G. 200 column. The in vivo DEAE/CM-PG was eluted in a single peak in a volume of approximately $150 \mathrm{ml}$., which was only slightly less than that obtained for the crude in vivo PG. In vitro DEAE/CM-PG was also eluted as a single peak with an elution volume identical to the original crude material, namely $154 \mathrm{ml}$. There were no significant differences in values for $\%$ lhydrolysis at $\eta R_{50}$ between either of the DEAE/ CM preparations nor were they different from in vitro CMI-PG, in vivo DEAE-PG or crude in vivo PG (Table 4).

\section{A comparison of cup-plate and reducing-group assays}

Because the crude in vitro $P G$ rapidly liberated monogalacturonic acid from sodium polypectate the presence of an exo-PG was suspected, but no exo-PG activity was observed in any of the purified preparations. The possibility that exo-PG was present in enzyme fractions but had escaped detection by cup-plate assay was therefore investigated. Fractions eluted from a CM-cellulose column following the application of crude in vitro $P G$ were assayed both by the cup-plate method and by determining the 
reducing groups released from $\mathrm{I} \mathrm{ml}$. of $0.5 \%(\mathrm{w} / \mathrm{v})$ sodium polypectate in $\mathrm{I}$ hr at $35.5^{\circ}$ by $0.1 \mathrm{ml}$. of each enzyme fraction. Cup-plate assay showed PG activity in two peaks as usual; $70 \%$ was recovered in the first peak (in vitro CMIPG) and approximately $33 \%$ was recovered in the second (in vitro CMII-PG). Only those fractions shown to contain PG by cup-plate assay liberated reducing groups from sodium polypectate. Reducing-group assay also showed that $70 \%$ of the applied PG was recovered in the first peak. However, the fractions in the second peak only contained approximately $3 \%$ of the applied PG, giving an over-all recovery of $73 \%$. Thus the activity of in vitro CMII-PG relative to the crude in vitro $P G$ as measured by reducing-group assay was only one tenth the cup-plate assay value. In a further comparison the activity of in vitro CMIIPG relative to the crude in vitro PG was found to be 3.3 and $5.3 \%$ by cup-plate and viscometric assays, respectively but only $0.3 \%$ by measurement of the rate of release of reducing groups.

\section{DISCUSSION}

The differences between the crude pectic enzymes produced in vivo and in vitro by the isolate of Penicillium expansum used in these studies were in the chemical bond hydrolysed rather than in the substrate attacked. Cole \& Wood (196I), however, found that other isolates of $P$. expansum, produced PMG in vitro and $P G$ in vivo. Differences in bond specificity for these enzymes is similar to those found between PG produced in vivo and in vitro by Rhizoctonia solani (Bateman, 1963); thus crude in vivo $P$. expansum $P G$ did not degrade sodium polypectate further than tetragalacturonic acid, whilst crude in vitro PG completely hydrolysed the substrate to monogalacturonic acid. It is doubtful whether all or even part of the PG activity observed in the crude in vitro preparation can be attributed to exo-PG. Liberation of monogalacturonic acid at an early stage in hydrolysis has been taken to be evidence for the presence of exo-PG (e.g. Hancock et al. 1964). However $\%$ hydrolysis at $\eta R_{50}$ for crude in vitro PG of $P$. expansum was considerably lower than for exo-PG produced by Coniothyrium diplodiella with pectic acid as the substrate (Endo, 1964). Whilst the value obtained would obviously depend on the initial chain length of the substrate, the figure of $6 \cdot 1 \%$ is probably too low for exo-PG alone. This value could represent the net result of the combined action of exo- and endo-PG; but the inability to distinguish more than one enzyme by molecular exclusion-chromatography of the crude material and the absence of a distinct exo-PG by ion exchange chromatography suggests that only one PG was present. From thermal inactivation studies Bateman (1963) also concluded that, in vitro, $R$. solani produced only one $\mathrm{PG}$, whose properties closely resembled the crude in vitro $P G$ of this study. No difficulties of classification pertain to the crude in vivo PG where all the observed activity can be attributed to endo-PG which did not significantly degrade the substrate beyond tetragalacturonic acid. A similar endo-PG has been described for yeasts (Luh \& Phaff, 1954).

One of the most interesting features of this study was that purification of both crude in vitro and crude in vivo PG of Penicillium expansum sometimes yielded enzymes whose properties did not correspond with the original material. Thus none of the ionexchange cellulose preparations of in vitro PG liberated significant quantities of a monogalacturonic acid. The high recovery values obtained indicate that no PG was lost during purification, for example by inactivation of exo-PG in the original crude material. Consistently high recoveries of PG from Fusarium oxysporum $\mathrm{f}$. sp. lyco- 
persici applied as a crude culture filtrate to DEAE-cellulose columns were also obtained by T. R. Swinburne \& M. E. Corden (private communication). From a comparison of the results of the various PG assay methods it was apparent that the cupplate technique was directly comparable with viscometric assay, but not necessarily with reducing-group assay. The cup-plate assay is relatively more sensitive to endo-PG than to exo-PG, and, moreover, enzymes with low percentage hydrolysis at $\eta R_{50}$, such as in vitro CMII-PG, produce proportionately larger halos than endo-PGs, such as in vitro CMI-PG, which hydrolyse the substrate more completely. This suggests that the differences between crude in vitro PG and in vitro DEAE-PG and CMI-PG might be due to changes in the properties of the enzyme molecule. If such changes resulted in an over-all increase in the viscometric activity the recovery values on a cup-plate assay would be high. The stability of PG at the $\mathrm{pH}$ value of the DEAE-cellulose columns is relatively low (Bateman, 1963) and some inactivation of in vivo PG may have taken place. If in vitro $P G$ were also inactivated at this $\mathrm{pH}$ value then the over-all recovery on DEAE-cellulose might have been even higher if this effect could have been avoided. With one exception, all changes in properties of enzyme preparations resulted in a decrease in $\%$ hydrolysis at $\eta R_{50}$. The exception to this was in vivo CM-PG, where a marked increase was obtained, and the final hydrolytic product was also changed from tetra- to tri-galacturonic acid. The somewhat low recovery values obtained for in vivo $\mathrm{PG}$ on $\mathrm{CM}$-cellulose may be related to enzyme inactivation, but the lower sensitivity of the cup-plate assay with such enzymes may also have affected the results.

Most preparations of Penicillium expansum in vivo and in vitro PG had similar properties. Thus crude in vivo-PG, DEAE-PG, DEAE/CM-PG, in vitro CMI-PG and DEAE/CM-PG were virtually identical in properties and might reasonably be assumed to be identical enzymes. The remaining preparations, all with properties of endo-PG, were however quite distinct from these and from each other. The simultaneous production of distinct forms of endo-PG has been described for various fungi (McClendon \& Kreisher, 1963; Endo, 1963). The three forms of endo-PG separated from bran cultures of Coniothyrium diplodiella also differed in the relative ability to reduce substrate viscosity in relation to the number of bonds hydrolysed (Endo, 1963). The existence of forms of endo-PG with different properties shows that some PGs are, paradoxically, 'more random' in their hydrolytic action than others, a similar situation to that described for cellulases (Nisizawa, Hashimoto \& Shibata, 1963). If the hydrolysis of $\alpha \mathrm{I}: 4$-glycosidic bonds in pectate substrates by endo-PG were truly random the percentage hydrolysis at $\eta R_{50}$ for most endo-PG preparations would be similar, since the number of bonds hydrolysed at $\eta R_{50}$ is a small proportion of the total. That this is not so is apparent from this and other studies (Endo, 1963).

The cause of the changes in enzyme properties during purification cannot be ascertained from the experiments reported here. Previous experiments with PG produced by Fusarium oxysporum $\mathrm{f}$. lycopersici suggested that dissociation phenomena took place on DEAE-cellulose, as indicated by Sephadex G200 separation of the products (Swinburne \& Corden, 1967). Whilst some slight differences were observed in elution volume on Sephadex G200 of in vitro and in vivo PG of Penicillium expansum following ion-exchange cellulose chromatography, these were much less than those observed with the Fusarium PG. The changes in property could have resulted either from alterations in the secondary or tertiary structure of the enzyme molecule as a result of the ionic conditions of separation (Steinburg \& Mihalyi, 1957), or, less 
probably, from the presence of substances which modified the mode of action of the enzyme. The explanation of these phenomena must await further experiments. If a range of properties can be evoked from one basic enzyme by appropriate treatments, the differences observed between in vivo and in vitro enzymes may also be attributable to different forms of the same enzyme. Bateman's (1963) work has shown that care must be taken in relating the properties of PG produced in vitro to the role of the enzyme in disease development in vivo, and this investigation suggests that care must be taken in extraction of enzymes produced in vivo to prevent changes from the native enzyme.

We wish to thank $\mathrm{Mr}$ M. Comer for his invaluable technical assistance throughout this work and Mr O’Neill (Biometrics Division, Ministry of Agriculture of Northern Ireland) for his advice on statistical problems.

\section{REFERENCES}

AKINREFON, O. A. (1967). Improved extraction of polygalacturonase in apple tissue rotted by Sclerotinia fructigena Aderh. \& Ruhl. Rep. agric. hort. Res. Stn. Univ. Bristol 1966, p. 168.

Ayers, W. A., Papavizas, G. C. \& Diem, A. F. (I966). Polygalacturonate transeliminase and polygalacturonase production by Rhizoctonia solani. Phytopathology 56, 1006.

Bateman, D. F. (1963). Pectolytic activities of culture filtrates of Rhizoctonia solani and extracts of Rhizoctonia-infected tissues of bean. Phytopathology 53, 197.

Bateman, D. F. \& Millar, R. L. (1966). Pectic enzymesin tissuedegradation. A. Rev. Phytopath.4, i 19.

Bate-Smith, E. C. \& Westall, R. G. (1950). Chromatographic behaviour and chemical structure. I. Some naturally occurring phenolic substances. Biochim. biophys. Acta 4, 427.

Cole, M. \& WoOD, R. K. S. (I96I). Pectic enzymes and phenolic substances in apples rotted by fungi. Ann. Bot. 25, 435.

Damle, V. P. (1952). Enzymatic study of certain parasitic fungi. J. India bot. Soc. 31, I2.

Demain, A. L. \& PhafF, H. J. (I957). Recent advances in the enzymatic hydrolysis of pectic substances. Wallerstein Lab. Commun. 20, I 19.

Dingle, J., REID, W. W. \& Solomons, G. L. (1953). The enzymatic degradation of pectin and other polysaccharides. II. The application of the cup-plate assay to the estimation of enzymes. $J$. Sci. Fd Agric. 4, 149.

ENDO, A. (1963). Studies on pectolytic enzymes of molds. Part VI. The fractionation of pectolytic enzymes of Coniothyrium diplodiella, (2). Agric. biol. Chem. 27, 751.

Endo, A. (1964). Studies on pectolytic enzymes of molds. Part XI. Purification and properties of exo-polygalacturonase. Agric. biol. Chem. 28, 639.

Granger, K. \& Horne, A. S. (1924). A method of inoculating the apple. Ann. Bot. 38, 212.

HANCOCK, J. G., MillaR, R. L. \& LoRBEER, J. W. (1964). Pectolytic and cellulolytic enzymes produced by Botrytis allii, B. cinerea, and B. squamosa in vitro and in vivo. Phytopathology 54, 928.

Husain, A. \& Kelman, A. (1959). Tissue is disintegrated. In Plant Pathology, ed. by J. C. Horsfall and A. E. Dimond, vol. I, p. 143. New York: Academic Press.

LuH, B. S. \& Phaff, H. J. (1954). Properties of yeast polygalacturonase. Archs Biochem. Biophys. 48, 23.

MrlleR, G. L. (1959). Use of dinitrosalicylic acid reagent for determination of reducing sugar. Analyt. Chem. 31, 426.

MCClendon, J. H. \& KREISher, J. H. (1963). Chromatography on cellulose phosphate of polysaccharide hydrolases from fungi. Analyt. Biochem. 5, 295.

NisizaWA, K., Hashimoto, Y. \& Shibata, Y. (1963). Specificities of some cellulases of the 'random' type. In Advances in Enzymic Hydrolysis of Cellulose and Related Materials, ed. by E. T. Reese. New York: Pergamon Press.

ReXoVA-Benkova, L. \& SlezariK, A. (1966). Isolation of extracellular pectolytic enzymes produced by Aspergillus niger. Colln Czech. chem. Commun. Engl. Edn 31, 122. 
Stannburg, D. \& Mihaly, E. (1957). The chemistry of proteins. A. Rev. Biochem. 26, 373.

SwINBURNE, T. R. \& CORDEN, M. E. (1967). Dissociation and recombination of a polygalacturonase complex during ion-exchange chromatography. Nature, Lond. 213, 286.

WARBURG, O. \& Christian, W. (1942). Isolierung und Kristallisation des Gärungsferments Enolase. Biochem. Z. 3ro, 384 .

Wood, R. K. S. (1955). Studies in the physiology of parasitism. XVIII. Pectic enzymes secreted by Bacterium aroideae. Ann. Bot. 73, 2.

Young, R. J. \& CoRden, M. E. (1964). Paper chromatography of galacturonic acids to determine polygalacturonase activity. Biochim. biophys. Acta 17, 124. 